\title{
GESTÃO SOCIAL NA EDUCAÇÃO PARA PESSOAS COM DEFICIÊNCIA
}

\author{
V. L. M. NUNES e C. M. MAGALHÃES \\ Centro Universitário UNA \\ verarosamorena@hotmail.com; claudiomagalhaes@uol.com.br
}

Submetido em 01/09/2015 - Aceito em 05/12/2016

DOI: $10.15628 /$ holos.2016.3370

\section{RESUMO}

Esta pesquisa foi realizada junto a sete universidades federais brasileiras com a finalidade de conhecer as ações estratégicas de gestão por elas desenvolvidas para atender aos alunos com deficiência, comparando suas ações internas quanto às políticas de educação inclusiva praticadas no processo de criação e consolidação dos respectivos núcleos de acessibilidade. $\mathrm{O}$ estudo centrouse na abordagem qualitativa através de pesquisa bibliográfica, documental e de campo, utilizando um estudo comparativo dessas instituições federais de ensino superior com a UFMG para verificar as ações efetivadas na gestão das políticas públicas quanto ao apoio didáticopedagógico aos discentes e, em especial, aos deficientes visuais. O estudo comprovou que quase todas as instituições pesquisadas estão cumprindo as recomendações legais orientadas pelo MEC e o processo de desenvolvimento das políticas de inclusão se dá nelas de forma diferenciada: enquanto que em cinco delas o processo já está consolidado, numa ainda está em implantação e em outra existem apenas ações fragmentadas. Além disso, os coordenadores têm tido a preocupação de tratar a educação inclusiva de forma mais ampla aliando as políticas de ações afirmativas com a inclusão social de alunos oriundos da escola pública, de indígenas e afrodescendentes assegurando o ingresso no ensino superior.

Palavras-Chave: gestão social, políticas públicas de inclusão, ensino superior, deficiência visual, núcleo de acessibilidade.

\section{SOCIAL MANAGEMENT IN EDUCATION FOR PEOPLE WITH DISABILITIES}

\begin{abstract}
This research was conducted with seven brazilian federal universities in order to meet the strategic management actions developed by them to attend students with disabilities, comparing its internal actions regarding inclusive education policies practiced in the creation and consolidation of their accessibility centers. The study focused on the qualitative approach through literature, documentary and field search, using a comparative study of these higher education federal institutions with the UFMG to check the actions that took effect on the management of public policies regarding the didactic and pedagogical support to students and in particular the visually impaired. The study revealed that almost all
\end{abstract}

institutions surveyed are fulfilling the legal recommendations guided by the MEC and the process of development of inclusion policies occurs differently among them: while in five of them the process is well established, is still in under deployment in one of them and in the other there are only fragmented actions. In addition, the coordinators of these accessibility centers have been concerned to deal with inclusive education more broadly combining the affirmative action policies to social inclusion of students from public schools, indigenous and Afro-descendant ensuring access to higher education.

keywords: social management, public policy of inclusion, higher education, visual impairment, center for accessibility. 


\section{INTRODUÇÃO}

As instituições de ensino superior no país têm dado atenção à inclusão das pessoas com deficiência, tanto na universidade como na sociedade; tal preocupação, no entanto, é relativamente recente e revela dificuldades de implantação de uma política de inclusão devidas a questões culturais; pois a educação inclusiva faz parte do movimento maior de inclusão social de todas as pessoas com deficiência que, ao logo da história, no panorama internacional e nacional, foram discriminadas e afastadas da convivência social.

$\mathrm{Na}$ educação, dentre alguns aspectos vistos como dificultadores de uma política inclusiva, é relevante apontar que a formação inicial dos docentes a temática da inclusão não estava prevista. Face a isso, o Ministério da Educação (MEC), ao impulsionar o desenvolvimento da matéria nas últimas décadas, orienta as universidades mediante uma legislação adequada e o financiamento de projetos para que elas criem as condições para uma mudança da realidade.

$\mathrm{O}$ estudo buscou conhecer como os serviços de apoio aos alunos com deficiência têm sido implementados nas universidades; os materiais didático-pedagógicos adaptados, acessibilidade arquitetônica, de transporte, e acessibilidade comunicacional e digital; além de verificar a gestão dessas atividades acadêmicas e administrativas realizadas pelos seus gestores. A pesquisa estudou também a experiência da Universidade Federal de Minas Gerais (UFMG), que oferece alguns serviços às pessoas com deficiência, como o Centro de Apoio ao Deficiente Visual - CADV. A autora realizou pesquisa junto a seis outras universidades públicas brasileiras fazendo um estudo comparativo entre elas e a UFMG. ${ }^{1}$ Nesta, dada à premência de gerenciar as políticas públicas de inclusão de maneira mais efetiva, busca-se hoje aprimorar e consolidar o núcleo de acessibilidade.

Além de investigar sobre os núcleos, tem-se como objetivo identificar as ações e parcerias que contribuem e as que dificultam o gerenciamento do trabalho de forma compartilhada, com possibilidades de participação intersetorial na execução das políticas internas na UFMG. Os objetivos específicos consistem em identificar ações políticas interdisciplinares e interinstitucionais de gestão que promovam a solução dos problemas decorrentes das práticas imediatistas e assistencialistas no apoio didático-pedagógico aos alunos com deficiência, para uma gestão social com características potencializadoras de desenvolvimento local; conhecer e analisar as ações das políticas de inclusão de alunos com deficiência implementadas pelas instituições federais de ensino superior (IFES) quanto à gestão dos serviços de apoio aos estudantes com deficiência visual (DV) dentro das recomendações da legislação; comparar as ações internas de várias IFES quanto às políticas de educação inclusiva praticadas no processo de criação e consolidação de seus núcleos de acessibilidade para dar o suporte pedagógico aos alunos.

Para esta pesquisa, buscou-se a legislação referente aos alunos com deficiência, em particular os deficientes visuais, baseado na experiência da pesquisadora. Utilizam-se os conceitos veiculados nos documentos do Ministério da Educação [MEC] (2007), segundo os quais, a "pessoa com deficiência [é] aquela que tem impedimentos de longo prazo, de natureza física, mental ou

\footnotetext{
${ }^{1}$ Dissertação de mestrado intitulada A política cega e o aluno sábio: gestão social como um caminho para a inclusão no ensino superior (2013).

2 Através do Aviso Circular n. 277/96 e da Portaria n. 1.679/99. (MEC, 1996).

${ }^{3}$ Biblioteca Digital e Sonora tem o objetivo de atender a demanda dos deficientes visuais coletando, reunindo,
} 
sensorial que, em interação com diversas barreiras, pode ter restringida sua participação plena e efetiva na escola e na sociedade" (MEC, 2007, p. 9); enquanto que cego é o que possui "desde ausência total de visão até a perda da projeção de luz" (Conceitos e características, 2013), e ainda, a visão subnormal, caso das pessoas que apresentam "desde condições de indicar projeção de luz até o grau em que a redução de acuidade interfere ou limita o seu desempenho visual" (Conceitos e características, 2013).

O trabalho centrou-se na abordagem qualitativa precedida de uma pesquisa bibliográfica sobre educação inclusiva no Brasil, no conceito de inclusão, nas políticas públicas e no papel do Estado para atender aos alunos no ensino superior, na legislação nacional, no conceito de gestão social, na educação inclusiva nas universidades federais num contexto de inclusão e, mais especificamente, no trabalho realizado pelo CADV enquanto espaço de inclusão. A pesquisa documental baseou-se em editais, decretos e documentos disponibilizados no site do MEC, bem como em resoluções normativas e em portarias referentes à institucionalização dos núcleos nas universidades pesquisadas.

O cenário do estudo foi constituído pela Universidade de Brasília (UnB), pela Universidade Federal de Ouro Preto (UFOP), pela Universidade Federal do Rio de Janeiro (UFRJ), pela Universidade Federal do Espírito Santo (UFES), pela Universidade Federal do Paraná (UFPR), pela Universidade Federal do Rio Grande do Sul (UFRGS) e pela UFMG. Os sujeitos da pesquisa foram professores coordenadores dos núcleos ou técnicos administrativos em educação responsáveis pela política de inclusão nessas universidades. No caso da UFMG, como não havia um núcleo de acessibilidade constituído dentro da estrutura organizacional, os sujeitos foram os docentes que lecionavam para alunos deficientes visuais e os próprios estudantes usuários do CADV.

\subsection{A educação inclusiva}

Signatário das decisões da Conferência Mundial de Educação para Todos (Declaração, 1990) e da Declaração de Salamanca - Sobre Princípios, Política e Prática para as Necessidades Educativas Especiais (Declaração, 1994), entre outras, o Brasil passa a orientar-se por seus princípios e decisões. A partir dessas diretrizes, emerge a educação inclusiva, possibilitando o acesso e a permanência de todas as crianças, jovens e adultos em todas as etapas e modalidades do sistema educacional, independentemente das condições de gênero, etnia, classe social ou deficiência (Menicucci, 2006). Falar de um direito universal à educação é referir-se ao direito humano da igualdade, respeitando-se ao mesmo tempo as diferenças. A igualdade a que se está reportando está relacionada com a igualdade na diferença, quer dizer, para que todos tenham a igualdade de oportunidades é preciso considerar as diferenças de cada um e de cada grupo (Rossetto, 2009). E de que forma promover isso senão tornando a escola um espaço inclusivo, pondo-se à disposição do aluno para que ele atinja os objetivos propostos para sua educação, garantindo assim condições de acessibilidade física e de recursos tecnológicos para responder às suas necessidades educacionais.

A partir do movimento de inclusão, reforçado pela Resolução CNE/CEB n. 02/01 que ratificou a obrigatoriedade da matrícula universal, os sistemas de ensino devem receber todos os alunos e preparar-se para atender também aos alunos com necessidades especiais (Aranha, 2004, p.22). Durante décadas as instituições educacionais praticaram o assistencialismo com os 
deficientes. Gradativamente começam a vigorar as políticas de inclusão na educação superior respaldadas nos dispositivos legais do $\mathrm{MEC}^{2}$, amplia-se, além disso, o debate sobre

o acesso a um sistema educacional inclusivo em todos os níveis pressupõe a adoção de medidas de apoio específicas para garantir as condições de acessibilidade, necessárias à plena participação e autonomia dos estudantes com deficiência, em ambientes que maximizem seu desenvolvimento acadêmico e social. (MEC, 2013).

\subsection{A gestão social e a educação}

A inclusão social configura-se num fator importante para o desenvolvimento da sociedade brasileira revelada pelas demandas de cidadãos, individualmente ou em grupos, e manifestada na luta pelos direitos à igualdade e por melhores condições de vida. A legislação nacional avançou, no entanto, na educação sua aplicabilidade apresenta dificuldades na implementação, que requerem mais estudos, troca de informações e aprofundamento dos conhecimentos por parte de todos os profissionais envolvidos.

Dessa forma, ao abordar e discutir as atividades referentes à educação inclusiva na perspectiva da gestão dos serviços que estão sendo oferecido aos alunos com deficiência e, em especial visual, procura-se transformar as dificuldades de gerenciamento de tais atividades em desafio para soluções que garantam a esses educandos serviços de qualidade para sua formação.

Nesse sentido, faz-se necessário dialogar e implementar no ambiente de trabalho práticas pautadas nos princípios de gestão social: “[...] processo gerencial dialógico no qual a autoridade decisória é compartilhada entre os participantes da ação (ação que possa ocorrer em qualquer tipo de sistema social - público, privado ou de organizações não-governamentais)" (Tenório, 2008, p.10).

Partimos da premissa de que esse caráter gerencial dialógico é fundamental na gestão das políticas públicas de inclusão dos discentes com deficiência visual diante da necessidade da interação entre os alunos/usuários e bolsistas, os professores e os gestores dos serviços de forma a atingir o objetivo final que é disponibilizar os textos adaptados para que os alunos acompanhem as aulas no mesmo ritmo que os demais colegas, assim como outras solicitações (adaptar mapas, lâminas, gráficos, figuras, slides, filmes, etc.). Isto remete às palavras da autora que considera "a gestão social, como campo de conhecimento interdisciplinar” (Maia, 2005, p.16). A gestão social aponta que os setores dedicados à inclusão devam atuar de forma mais ampla, com mais autonomia gerencial e fazendo parte da estrutura organizacional da universidade, visando promover e fortalecer os processos democráticos de formulação e gestão de políticas públicas de inclusão das pessoas com deficiência. Outro autor reforça esse pensamento: “Assim, para uma participação no sentido de partilha de poder, envolvendo a formulação e a implementação de políticas públicas, torna-se importante encontrar mecanismos capazes de institucionalizar os processos participativos" (Tenório, 2008, p.23).

\footnotetext{
${ }^{2}$ Através do Aviso Circular n. 277/96 e da Portaria n. 1.679/99. (MEC, 1996).
} 
Portanto, é preciso estreitar as relações entre educação e participação e favorecer o desenvolvimento do sujeito participativo e ativo através da informação e do conhecimento sobre sua realidade, possibilitando sua transformação e a do seu entorno.

Assim, quando se avalia o cenário de exclusão a que os deficientes foram submetidos, concorda-se com Demo (1993) que valoriza a participação como conquista. A mudança da situação atual passa igualmente pelo investimento na formação de profissionais da educação. Para isso, cabe à universidade, como agente gestor, tomar a iniciativa da transformação, impulsionar o corpo docente para agir com práticas educativas na promoção da inclusão, valorizando a diversidade no ambiente acadêmico e administrativo. De acordo com o MEC,

[...] à gestão da educação superior compete o planejamento e a implementação das metas de acessibilidade preconizadas pela legislação em vigor, bem como o [...] financiamento das condições de acessibilidade deve integrar os custos gerais com o desenvolvimento do ensino, pesquisa e extensão. (MEC, 2013).

Na esfera pública, destaca-se “o Estado como 'poder público' pela tarefa que assume de promover o bem público, o bem comum a todos os cidadãos” (Pereira \& Rigatto, 2011, p.22), a universidade é um órgão desse Estado. Nesse caso, o que é o bem público? É proporcionar às pessoas com deficiência as condições de estudar em situações favoráveis de desenvolvimento, ou seja, igualdade de direitos e tratamento de acordo com as suas necessidades. Para isso, as IFES devem estabelecer uma política de acessibilidade contemplando o desenvolvimento da instituição; no planejamento e execução orçamentária, no quadro de profissionais, dentre outros. (MEC, 2013).

\subsection{Políticas públicas e o papel do Estado}

Sob o impulso dos movimentos sociais e por normativas internacionais, iniciam-se modificações na legislação, as pessoas com deficiência sentem-se crescentemente empoderadas e buscam sua inserção no ensino universitário com vistas a um comportamento mais ativo de participação como cidadãs nas áreas da saúde, trabalho, educação e lazer, alcançando melhorias em sua própria vida e na de suas famílias.

Para atender esses educandos, a legislação orienta que as IFES devem tomar as providências para efetivar as adaptações necessárias no sentido de garantir o acesso, a permanência e a conclusão de seus cursos e propondo projetos para eliminar as barreiras pedagógicas, de comunicação e informação, arquitetônicas aplicando a acessibilidade universal. Quanto à legislação, destaca-se a SECADI/SESu - Programa de Acessibilidade na Educação Superior, 2005 a 2011 (MEC, 2013) que foi desenvolvido pelo MEC para viabilizar a implantação ou consolidação de núcleos de acessibilidade nas universidades federais. Diante das disposições legais mencionadas, o Estado assume seu papel de dar as diretrizes para a implementação de políticas públicas de educação inclusiva no ensino universitário com um papel regulador, difusor das normas e fiscalizador. Cabe à universidade criar mecanismos internos para cumprir a legislação específica para diminuir as desigualdades de oportunidades das pessoas com deficiência. O Estado se mantém e se reproduz através das instituições, uma das quais é a universidade, formando profissionais para a sua manutenção e desenvolvimento, produzindo e difundindo o conhecimento científico. 


\subsection{As universidades federais no contexto da inclusão}

As primeiras iniciativas brasileiras a tratar da política de educação inclusiva dos alunos com deficiência no ensino superior foi regulamentada pelo MEC em sua Secretaria de Educação Especial (SEESP) através da Portaria n. 1.793/94, do Aviso Circular n. 277, em 1996, da Portaria n. 1.679/99 (MEC, 1994; 1996; 1999), entre outras; assim, a legislação foi sendo aprimorada para atender os níveis de educação nacional garantindo o direito de todos ao ensino superior. Em 2005, o Governo Federal lançou o Incluir (Programa de Acessibilidade na Educação Superior), priorizando as propostas de ações para a criação e a consolidação de núcleos de acessibilidade nas universidades federais, (MEC, 2013). Em 2007, passou a integrar as ações propostas pelo Plano do Desenvolvimento da Educação com o objetivo de incentivar e fortalecer esses núcleos. Nos anos posteriores, o MEC publicou os editais convocando as universidades a promoverem a educação inclusiva.

No entanto, os estudos apontam que a legislação, se bem que necessária, é insuficiente para dar conta das complexas mudanças para transpor as barreiras que impedem ou freiam o acesso e a permanência das pessoas com deficiência no ensino superior:

[...] muitas universidades começaram a criar ações que garantam acessibilidade em sua estrutura arquitetônica, [...] revelam que o atendimento apenas à infraestrutura espacial não consegue minimizar a exclusão destes alunos no ensino superior. Aspectos como as condições didático-pedagógica (sic) de trabalho de professores, comprometidos pela falta de tecnologias de ajuda para operacionalização de um processo de aprendizagem e inclusão deste aluno de modo pleno, encontram-se entre os principais obstáculos. (Rocha \& Miranda, 2009, p. 31).

Nesse caso, busca-se dialogar com os envolvidos nos projetos das instituições sobre a temática da educação inclusiva com foco na criação e gerenciamento dos serviços ofertados aos alunos, para subsidiar os estudos da investigação que se pretende realizar. Aprender com os erros e com a demora na implementação da educação superior para todos encurtará o caminho para uma universidade mais democrática e participativa que inclua todos.

\section{A PESQUISA}

Os dados levantados nas entrevistas e questionários junto aos coordenadores das universidades permitiram comparar as ações efetivadas quanto à criação de núcleos de acessibilidade, que levam a assegurar a permanência e a conclusão de curso dos estudantes com deficiência e isso, tanto na comparação entre as IFES pesquisadas, quanto na comparação delas com a UFMG. A investigação sobre as políticas de educação inclusiva nas instituições selecionadas teve como orientação o Programa Incluir do MEC (MEC, 2013). Sua existência está relacionada com a definição de uma política de educação inclusiva instituída pelos conselhos da universidade e regulamentada por resoluções.

A composição da equipe do núcleo de acessibilidade das IFES pesquisadas é multidisciplinar. $\mathrm{O}$ que chamou a atenção também foi o contingente de profissionais envolvidos nas equipes para dar conta da complexidade e do volume de serviços destinados a esses usuários. 
A base legal para instituir políticas públicas de educação inclusiva está referendada na postura política dos gestores das instituições inicialmente através da resolução ad hoc, portanto ela regulariza não só o núcleo, mas a inclusão desses alunos no espaço acadêmico e amplia a responsabilidade, para além do núcleo.

Diante disso, há princípios na política de educação inclusiva e orientações para a gestão que envolvem ações efetivas de participação, planejamento e organização de recursos e serviços promotores da acessibilidade e eliminadores das barreiras arquitetônicas, atitudinais, etc. Consequentemente, necessita-se viabilizar as condições favoráveis de acessibilidade, implementado-as nas instituições mediante planos, projetos e parcerias.

As IFES pesquisadas possuem alunos com deficiência na graduação e na pós-graduação, aos quais oferecem apoio didático-pedagógico de acordo com suas necessidades educacionais.

A política de inclusão dessas universidades começa já no vestibular. Em três delas, os procedimentos são da mesma natureza; após a aprovação, faz-se contato com os alunos e o encaminhamento para os serviços especiais, exceto na UFPR, cuja ação precede o vestibular com a análise e triagem dos alunos.

A gestão desses serviços nessas instituições encontra-se bem estruturada e implementada, viabilizando condições e serviços para o desenvolvimento das atividades acadêmicas dos estudantes, com uma articulação intersetorial para executar as ações. De fato, os setores acadêmicos e administrativos, quando envolvidos, criam uma rede de colaboradores. A UFRGS, por exemplo, lança mão de bolsistas do curso de psicologia que formam uma rede sediada em suas bibliotecas.

Quanto ao atendimento aos deficientes visuais, a pesquisa buscou conhecer mais detalhes e observou-se que as universidades dispõem de uma estrutura robusta composta de técnicos, professores, alunos bolsistas, além de recursos e equipamentos. Seis universidades adaptam textos transcritos em braille e digitalizados para os cegos, enquanto que o material gravado é utilizado por cinco delas e, para alunos com baixa visão, cinco oferecem a possibilidade da impressão ampliada.

De uma forma geral, é importante ressaltar o papel relevante que os recursos tecnológicos desempenham no ensino-aprendizagem e na participação desses estudantes nas atividades acadêmicas. De tal forma que, em muitos casos, segundo Rodrigues e Alves (2013), sua participação plena só pode ser garantida mediante recursos de tecnologia assitiva, entre outros, não só no ambiente escolar, mas para permear todos os processos de aprendizagem dos quais esses sujeitos podem usufruir ao longo de suas vidas.

A complexidade das atividades educacionais torna necessária a elaboração de estratégias de ação, planejamento, organização e definição de prioridades, o que exige ações articuladas de gestão das atividades estudantis ao longo de todo o percurso universitário. Tais estratégias dialogam com os princípios da gestão social que evidenciam a participação como um dos pilares dessa gestão. Esse processo é visto por Tenório (2008, p.27) “como um processo intersubjetivo, dialógico, onde todos têm direito à fala"; para dar resposta às necessidades educacionais desses alunos, a pesquisa revelou que é imprescindível dialogar com as várias áreas do conhecimento, através de ações departamentais e setoriais. $\mathrm{Na} U \mathrm{UnB}$, segundo entrevista, o programa coordena as ações, mas os departamentos e setores devem fazer ações pontuais porque há as especificidades. Na Faculdade de Educação, o Programa de Apoio às Pessoas com Necessidades Especiais mantém o Laboratório para Deficiente Visual, que trata da edição e adaptação de material e, na Biblioteca Central a 
Biblioteca Digital e Sonora, ${ }^{3}$ que disponibiliza um serviço diferenciado e qualificado em relação às demais universidades com número razoável de profissionais.

Quanto aos alunos com deficiência auditiva, há atividades com atendimento mediado por intérpretes de Libras em sala de aula; supervisão de um especialista para acompanhar o trabalho dos intérpretes. Na UFRGS, há um projeto de tutoria em que o próprio aluno sugere um colega para ser seu monitor. Além disso, na maioria dos eventos, há interpretes, como em aulas inaugurais, aulas magnas, seminários, visitas a museus e atividades de extensão. Na UFMG, no entanto, não se estruturou um serviço adequado de atendimento em Libras.

Quanto aos alunos com deficiências físicas e neuromotoras, as universidades elaboram projetos para reformas e adaptação dos espaços físicos, construção de rampas, adaptação de cadeiras e mesas. A UFRGS criou uma comissão de acessibilidade para efetuar as intervenções em parceria com os setores administrativos. Na UFMG, a acessibilidade arquitetônica ainda não foi solucionada.

Os dados revelados na pesquisa apontaram que os projetos foram financiados em geral pelo Programa Incluir em parceria com a Secretarias de Educação Superior (SESu), a Secretaria de Educação Continuada, Alfabetização, Diversidade e Inclusão (SECADI), assegurando investimentos na qualidade da educação inclusiva ao longo dos últimos oito anos. Os núcleos de acessibilidade que participaram desta pesquisa preocuparam-se em tratar a educação inclusiva de forma mais ampla, congregando as políticas afirmativas; investem em programas, planos e projetos de formação dos profissionais envolvidos com a inclusão e também em comunicação e informação através de publicação das pesquisas. Na UFMG, há uma carência de articulação intersetorial na implementação das políticas de inclusão.

Os dados da pesquisa realizada entre os docentes da UFMG permitem dizer que a política de inclusão é pouco conhecida entre os professores, os colegiados, a administração central e entre os setores administrativos não há articulação e uma inter-relação entre as ações gerenciais e os dados referentes aos alunos são pouco conhecidos. Verifica-se, outrossim, que, como não há uma política claramente definida orientada para a inclusão de todos os alunos com deficiência e, em particular, dos deficientes visuais, também falta uma gestão compartilhada dos setores e serviços concernentes à deficiência. Em grande parte, talvez isso se deva à ausência de uma política de formação de professores para o ensino superior. Nesse sentido, é importante observar que esses docentes também apresentam sequelas na sua formação inicial e que se estendem na sua formação continuada. Assim, nos cursos de formação de professores oferecidos pela universidade, é importante promover ações para eliminar as barreiras atitudinais, de comunicação e as barreiras pedagógicas. A qualidade da formação inicial e continuada dos educadores implica em entender a inclusão como processo permanente de capacitação dos professores, para promover o desenvolvimento pedagógico.

\footnotetext{
${ }^{3}$ Biblioteca Digital e Sonora tem o objetivo de atender a demanda dos deficientes visuais coletando, reunindo, organizando e armazenando materiais em formato digital devidamente adaptados para os programas ledores de tela, além de livros gravados com uso da voz humana. (Biblioteca, n.d.).
} 


\section{CONSIDERAÇÕES FINAIS}

A maioria das universidades públicas pesquisadas criou núcleos de acessibilidade que se consolidaram mediante equipes e um trabalho multidisciplinar instituído pelos respectivos conselhos e regulamentado por resoluções. $\mathrm{O}$ estudo mostrou que elas reforçam o direito à educação superior para pessoas com deficiência e demonstram a importância dos requisitos legais da acessibilidade preconizados pelo MEC. Os projetos das universidades foram financiados especialmente pelo Programa Incluir vinculado às Secretarias de Ensino Superior e a de Educação Especial do MEC. Com o olhar ainda mais amplo, os núcleos dessas universidades trataram da inclusão com políticas afirmativas e buscando uma educação de qualidade para todos, com a garantia da inclusão de indígenas, afrodescendentes e alunos provenientes da escola pública mediante uma política de reserva de cotas para o ingresso no ensino superior, resgatando uma dívida histórica com esses segmentos da população.

As instituições federais de ensino superior que participaram da pesquisa têm alunos com necessidades educacionais especiais na graduação e na pós-graduação, recebendo o apoio didáticopedagógico de acordo com suas demandas. O estudo revelou que esse tipo de apoio didático constitui-se num trabalho de alta complexidade, exigindo um suporte simultâneo e conjugado de várias especialidades num clima de cooperação e solidariedade.

A pesquisa revelou que as ações gerenciais nos núcleos de acessibilidade atendem aos princípios da gestão social com a efetiva participação plural no planejamento e na organização de recursos e serviços para a promoção da acessibilidade e a eliminação das barreiras que constituem ainda obstáculos para práticas pedagógicas mais inclusivas.

Quanto ao atendimento aos alunos com deficiência visual, o estudo constatou que as universidades possuem um trabalho bem estruturado, com equipes de profissionais qualificados de várias áreas, com recursos e equipamentos adequados para concretizar o apoio educacional especializado, o que revela um dos princípios da gestão social. A situação do CADV, no entanto, tem uma estrutura de poucos recursos humanos comparada com núcleos de outras universidades. Por isso, é premente a criação de um núcleo institucionalizado de acessibilidade orientado por uma gestão social, ao qual o CADV estaria integrado, dada a sua larga experiência no atendimento aos alunos cegos e com visão subnormal. Mas torna-se vital agregar outros profissionais para ampliar e aprimorar seu trabalho, contribuindo assim para uma universidade com uma formação integral que valoriza as diferenças numa sociedade diversa e democrática.

Dado o parco conhecimento da prática da inclusão por parte dos docentes, alunos e dos próprios colegiados sem ações administrativas e acadêmicas articuladas, o estudo apontou que não há uma política claramente definida orientada para a inclusão de todos os alunos e, em particular, dos deficientes visuais. A instituição carece também de uma rede de colaboradores constituída pelos setores e serviços que atendam a esses discentes. Apesar disso, no entanto, a pesquisa revelou que o Centro de Apoio ao Deficiente Visual tem conseguido atender às expectativas da maior parte dos docentes quanto à preparação do material didático. $\mathrm{O}$ estudo demonstrou que é preciso investir na formação e treinamento dos docentes e técnicos administrativos para familiarizá-los com práticas pedagógicas inclusivas. 
As ponderações e propostas desse olhar, elencadas e discutidas neste artigo, já tiveram sua aplicabilidade testada quando implementadas no Centro de Apoio na UFMG pela prática longamente levada a efeito no Centro.

A pesquisa revelou que a participação dos alunos com necessidades educacionais especiais no ambiente acadêmico é ainda pouco relevante, ou seja, há uma carência de ações que promovam o desenvolvimento acadêmico e social deles na instituição. Só através da participação poderá haver um empoderamento deles enquanto sujeitos de sua própria educação, participando como membros ativos da comunidade e da sociedade.

O estudo também apontou que as instituições precisam ampliar os espaços de discussão sobre a temática da inclusão, interagir com os alunos interessados, os docentes e os profissionais envolvidos, o que trará mudanças a partir de um modelo de gestão social, um processo gerencial dialógico em que a elaboração e a implementação de políticas sejam compartilhadas entre os participantes na aplicação das políticas públicas, já que a inclusão só é social e educativa se for uma construção coletiva. $\mathrm{O}$ artigo não pretende indicar todas as possíveis soluções para as situações problemas levantadas, quer apenas ampliar o debate e abrir novas portas com novos olhares, em busca da melhoria da qualidade de vida e de ensino.

\section{REFERÊNCIAS}

Aranha, M. S. F. (Org.). (2004). Educação inclusiva: a fundamentação filosófica. Brasília: MEC. Recuperado em 18 de novembro de 2013 de $<$ http://portal.mec.gov.br/seesp/arquivos/pdf/fundamentacaofilosofica.pdf $>$.

Biblioteca Digital e Sonora. (n.d.). Recuperado em 7 de novembro de 2013 de $<$ http://bds.bce.unb.br/>.

Conceitos e características da deficiência visual. (2013, 18 de abril). Recuperado em 3 de dezembro de $2013 \quad$ de $\quad<$ http:// www.portaleducacao.com.br/pedagogia/artigos/44645/conceitos-e-caracteristicas-da-deficienciavisual $>$.

Declaração de Salamanca. (1994). Sobre Princípios, Políticas e Práticas na Área das Necessidades Educativas Especiais. Procedimentos-padrões das nações unidas para a equalização de oportunidades para pessoas portadoras de deficiências, A/RES/48/96, Resolução das Nações Unidas adotada em assembleia geral. [1996?]. Recuperado em 24 de fevereiro de 2013 de $<$ http://portal.mec.gov.br/ seesp/arquivos/pdf/salamanca.pdf $>$.

Declaração Mundial sobre Educação para Todos: satisfação das necessidades básicas de aprendizagem. (1990). UNESCO.

Demo, P. (1993). Participação é conquista: noções de política social participativa. São Paulo: Cortez.

Maia, M. (2005, dezembro). Gestão social: reconhecendo e construindo referenciais. Textos \& Contextos, (4), 1-18. Recuperado em 5 de junho de 2012 de $<$ http://revistaseletronicas.pucrs.br/ojs/index.php/fass/article/viewFile/1010/790>.

Menicucci, M. C. (2006). Educação inclusiva: possibilidades e desafios. In M. C. Menicucci et al., Educação especial inclusiva (pp.17- 40). Belo Horizonte: PUC Minas Virtual. (Livro-texto do curso 
online Educação Especial Inclusiva, oferecido pela PUC Minas).

Ministério da Educação. (1996). Aviso Circular n. 277/MEC/GM, de 8 de maio de 1996. Brasília. $\begin{array}{lllllll}\text { Recuperado em } & 24 & \text { de } & \text { fevereiro } & \text { de } & 2013 & \text { de }\end{array}$ $<$ http://portal.mec.gov.br/seesp/arquivos/pdf/aviso277.pdf $>$.

Ministério da Educação. (1999). Portaria n. 1.679, de 2 de dezembro de 1999. Dispõe sobre requisitos de acessibilidade de pessoas portadoras de deficiências, para instruir os processos de autorização e de reconhecimento de cursos, e de credenciamento de instituições. Brasília, DF, 1999. $\begin{array}{lllllll}\text { Recuperado em } & 24 & \text { de } & \text { fevereiro } & \text { de } & \end{array}$ $<$ http://portal.mec.gov.br/sesu/arquivos/pdf/c1_1679.pdf $>$.

Ministério da Educação. (2007). Secretaria de Educação Especial. Política Nacional de Educação Especial na perspectiva da educação inclusiva. Brasília. Recuperado em 17 de abril de 2013 de $<$ http://portal.mec.gov.br/seesp/arquivos/pdf/politica.pdf $>$.

Ministério de Estado da Educação e do Desporto. (1994). Portaria n. 1.793, de dezembro de 1994. Brasília. Recuperado em 22 de março de 2013 de $<$ http://portal.mec.gov.br/seesp/arquivos/pdf/port1793.pdf $>$.

Ministério da Educação. (2013). Secretaria de Educação Continuada, Alfabetização, Diversidade e Inclusão. Secretaria de Educação Superior. Documento orientador: Programa Incluir Acessibilidade na Educação Superior [S.l.]. Recuperado em 24 de fevereiro de 2013 de $<$ http://portal.mec.gov.br/index.php?option=com docman\&task=doc_download\&gid=12737\&ltemid=>.

Pereira, J. R., \& Rigatto, S. H. (2011). Gestão social de políticas públicas no contexto das relações entre Estado e sociedade moderna. In J. R. Pereira (Org)., Gestão social de políticas públicas. Lavras: Ed. UFLA.

Rocha, T. B., \& Miranda, T. G. (2009). A inclusão de alunos com deficiência no ensino superior: uma análise de seu acesso e permanência. In F. Díaz et al. (Org)., Educação inclusiva, deficiência e contexto social: questões contemporâneas (pp.27-37). Salvador: EDUFBA.

Rodrigues, P. R., \& Alves, L. R. G. (2013). Tecnologia assistiva - uma revisão do tema. Holos, 6, 170-180. Recuperado em 5 de agosto de 2015. de <http://www2. ifrn.edu.br/ojs/index.php/HOLOS/article/view/1595/765>.

Rossetto, E. (2009). Sujeitos com deficiência no ensino superior: vozes e significados. Tese de Doutorado. Faculdade de Educação, Universidade Federal do Rio Grande do Sul, Porto Alegre.

Tenório, F. G. (2008). (Re)visitando o conceito de gestão social. In F. G. Tenório, Gestão social: metodologia, casos e práticas. Rio de Janeiro: FGV. 